\title{
A Survey of Undergraduate Students Utilizing an Interdisciplinary Labora- tory Building
}

\section{Dr. Darby Lantz Holtzhower, Oklahoma State University}

Lantz Holtzhower is currently an Assistant Professor serving the Construction Engineering Technology department within the College of Engineering, Architecture, and Technology at the Oklahoma State University in Stillwater, Oklahoma. He completed his Ph.D. in Construction Management at the M.E. Rinker, Sr. School of Building Construction in Gainesville, Florida at the University of Florida. His research interests include water conservation, rainwater harvesting, stormwater recycling, and overall sustainable water use within buildings. The current focus of his research is the implementation effects of low impact developments, net-zero schools and residences, and constructed wetlands into the built environment. He holds a Master's degree in Building Construction and a Bachelor's degree in Architecture, both from the University of Florida. Dr. Holtzhower has 9 years of professional construction experience including commercial construction management, electrical contracting and management with a fire protection contractor. The wide variety of projects includes a flagship institutional project, several municipal projects, K12 projects, office buildings, residential amenities and agricultural storage warehouses. He is a licensed Certified Building Contractor in the State of Florida and a member of the USGBC of Oklahoma.

\section{Dr. Rachel Mosier P.E., Oklahoma State University}

Dr. Rachel Mosier is an Assistant Professor at Oklahoma State University. Her research interest is the cost of sustainable construction and sustainable infrastructure. Other research interests include technology in the classroom. 


\title{
"A survey of undergraduate students utilizing an interdisciplinary laboratory building"
}

\begin{abstract}
Universities with graduate programs typically focus on graduate research assistants seeking master's and doctoral degrees. However, this focus can overlook students early in their college careers. As an introduction to research, the College of Engineering, Architecture and Technology devoted particular resources to undergraduate research and education. By creating an interdisciplinary laboratory environment where students can experience research first hand in their first few years in college, undergraduates can develop interests for research, regardless of their chosen engineering field.
\end{abstract}

Although the interdisciplinary concept was promoted at the Dean level, the coursework is implemented at the faculty level. Faculty was encouraged to provide training videos on all of the equipment, so students can train on their own time, rather than being constrained by a traditional lab and lecture framework. This allows students to start learning about research before taking courses on the subjects, freeing up their time to focus on multi-disciplinary problems.

This paper describes student participation in the lab and faculty use of the lab. Further the opportunities for interdisciplinary learning have been identified. As the laboratories available continue to come online in this new building, the usefulness and applicability of the interdisciplinary building will be revealed. A survey was conducted of current students to better understand their perceptions of the multi-function facility. In addition to the survey questions about the building itself, several questions aimed to understand the student's individual perceptions as it pertains to inclusivity and success in learning with interdisciplinary measures. The results of the study indicate that students do not necessarily feel cohorts of similar majors and personalities is a deterrent in learning outcomes.

Introduction

A newly constructed undergraduate research laboratory was completed in 2018 at Oklahoma State University for the College of Engineering Architecture and Technology (CEAT). Although the building was funded by CEAT, the intent was that interdisciplinary work would be performed in this lab. Students from the Colleges of Business and Arts and Sciences are encouraged to utilize the space to participate in interdisciplinary research. The new lab spaces were to replace existing older spaces, many of which were in outdated buildings which were due to be demolished. Materials labs which were previously discipline specific were now combined, so all majors would be able to perform the exact same experiments using brand new equipment.

As part of the building design and prior to construction, many disciplines were invited to give feedback on needs and think about how the lab could be a multi-functional space. Concurrently with the standard design practices, faculty participated in the laboratory design functionality of the building. Faculty met to determine how different majors could share spaces, equipment and lab exercises to the betterment of the college. A variety of positive and negative factors were identified. Some of the potential solutions to challenges have not been implemented as of yet. 
Although the administration and faculty were working to provide new spaces and equipment, students were not a part of the process. Initial feedback from students indicated a preference to the old spaces, even if there were significant issues to overcome. The focus of this research is on the student perceptions of the new lab, specifically if they believe it encourages interdisciplinary study.

Many major departments pride themselves as being separate and unique from other programs within a given university or as compared to outside university programs. This instills a sense of pride in the program but can be exclusive and elitist. To that point, exclusivity can result in a sense of community in a cohort, like with degree specific living-learning communities (Goldman 2012, Spanierman et al. 2013 and Wawrzynski and Jessup-Anger 2010). Living-learning communities use the traditional dormitory style university living and allow students to selfsegregate on a basis of major area of study. This ability to easily identify others with similar interests increased the sense of community for students (Spanierman et al. 2013). Learning communities include students scheduled in at least two of the same courses, both academic and social activities which are often facilitated by faculty (Goldman 2012). Using the example of a living-learning community, belonging to a cohort may provide a sense of belonging. Therefore, to pair with the interdisciplinarity question, a question of inclusivity was posed.

Some research has been performed on interdisciplinary courses in engineering. The research focuses on pedagogy and course design over the student perception of the interdisciplinary nature of the course (Johnson et al. 1995, Schaub et al. 1999, and Sharma, A. 2009). Similarly, inclusion is not a focus of most interdisciplinary engineering education research. However, diversity and inclusion are a separate focus in engineering education (Klotz et al. 2014 and Foor et al. 2007). As indicated in the literature, there are gaps in diversity and inclusion which are systemic. When the existing faculty at an institution are all white males, it can be difficult for students to see themselves in the same role (Chubin et al. 2005 and Foor et al. 2007).

Based on no known study of inclusion and diversity when combined with interdisciplinary studies, a survey was created. The survey seeks to determine if student perception of a shared space with other major fields of student was more inclusive. Further, the survey seeks to identify whether students feel more included when in a smaller group which is defined as their major cohort. An interesting juxtaposition is the need for interdisciplinary work especially for students who will work professionally in teams, while also encouraging a cohort which can result in higher grades, increased course completion and graduation retention rates (Goldman 2012).

For students in architecture, construction and certain engineering careers, professional interdisciplinary teamwork is a must. Studies have been performed on student learning styles in these various building career paths which indicate that these students may be more sensing than intuitive (Mosier et al. 2017 and Felder and Silverman 1988). In a similar study, Visual and Kinesthetic learning styles were preferred by a similar population (Nelson and Lawson 2013).

Methodology 
A simple survey was written to collect information from undergraduate students within the college. Initially, it was intended that the targeted population would be only those that have had structured lab courses within the new building, but due to the nature of discussion above surrounding inclusion, the authors felt it appropriate to cast the net wider. Therefore, the survey shown below was given to six undergraduate courses containing over three hundred students total. These courses ranged from freshman level to senior capstone design classes.

\begin{tabular}{|l|l|c|c|c|}
\hline & Question & & & \\
\hline 1 & Have you ever been in the Endeavor laboratory building? & Yes & No & \\
\hline 2 & Have you had structured lab classes in the Endeavor? & Yes & No & \\
\hline 3 & Have you had major specific lab classes in other buildings? & Yes & No & \\
\hline 4 & Does your program/ department have its' own lab building? & Yes & No & \\
\hline 5 & If yes, do you feel included in your program/ department lab building? & Yes & No & \\
\hline 6 & In general, do you feel isolated from other students in you Major? & Yes & No & \\
\hline 7 & In general, do you feel isolated from other students in your College? & Yes & No & \\
\hline 8 & $\begin{array}{l}\text { Do you feel the Endeavor, (an interdisciplinary laboratory building) } \\
\text { helps with inclusion? }\end{array}$ & Yes & No & N/A \\
\hline 9 & Have you participated in interdisciplinary programs/ courses & Yes & No & \\
\hline 10 & Do you feel the interdisciplinary courses increase learning? & Yes & No & N/A \\
\hline
\end{tabular}

The questions were intended to be completed in a single sitting, in less than five minutes. The first two questions were intended to frame the student's thinking around the new undergraduate laboratory building. It is defined as an interdisciplinary lab as it services multiple majors and programs with the college. The next two questions were to establish if the student has other lab courses and a place that the department or program in which these courses are taken typically conducts laboratory classes. The next two questions concerning isolation are meant to address the notion of silos within academic circles, and whether or not the student views this as a negative characteristic. The use of the word 'isolation' is intentional, as students should immediately attach this with a negative connotation. If the student feels silos and separation from other programs or majors is a negative attribute, it may surface as a 'Yes' response. A negative response may suggest pride and identity in a certain location of single program as a positive characteristic. The next question specifically ties the Endeavor laboratory to the idea of inclusion and increased learning with interdisciplinary collegiality.

The surveys also include three additional demographic questions to categorize the results further. The first asks the students' major, to identify various programs and majors in the college. The other two identify the students' gender and race. This is not for identification purposes, only for further exploration in future studies.

Results

In total, 219 responses were collected. The overall responses to the questions are shown below in Figure 1.1 coincide with the questions in the table above. $74 \%$ of the respondents indicated they have been inside the Endeavor laboratory building, but $75 \%$ stated they have not had structured lab classes in the building. This is due to the many open houses and marketing events 
put on by the college to encourage the familiarization of the building. It is also a 24 hour building that is inviting to study groups, so perhaps some of these visitors to the building have utilized these spaces. The building itself is also used as a teaching tool, housing individual impromptu tours in architecture and construction classes to view the materials. See picture 1.1. Although it is difficult to pinpoint the reason for visiting the building, it is clear from the data that more students have visited the building informally, perhaps inquisitively.

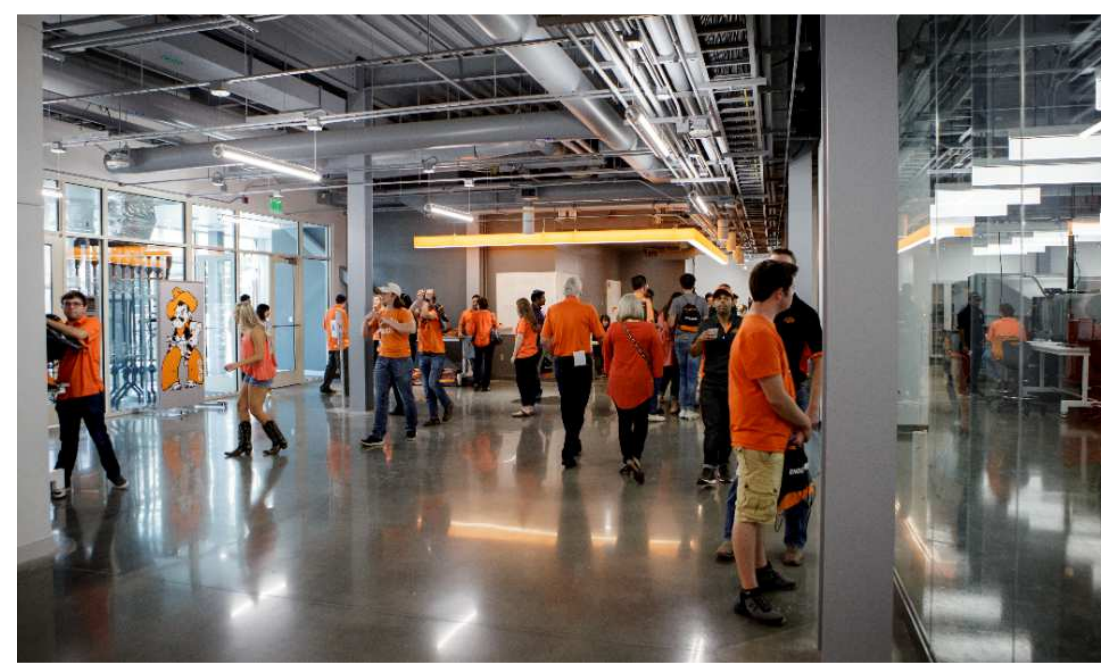

Picture 1.1

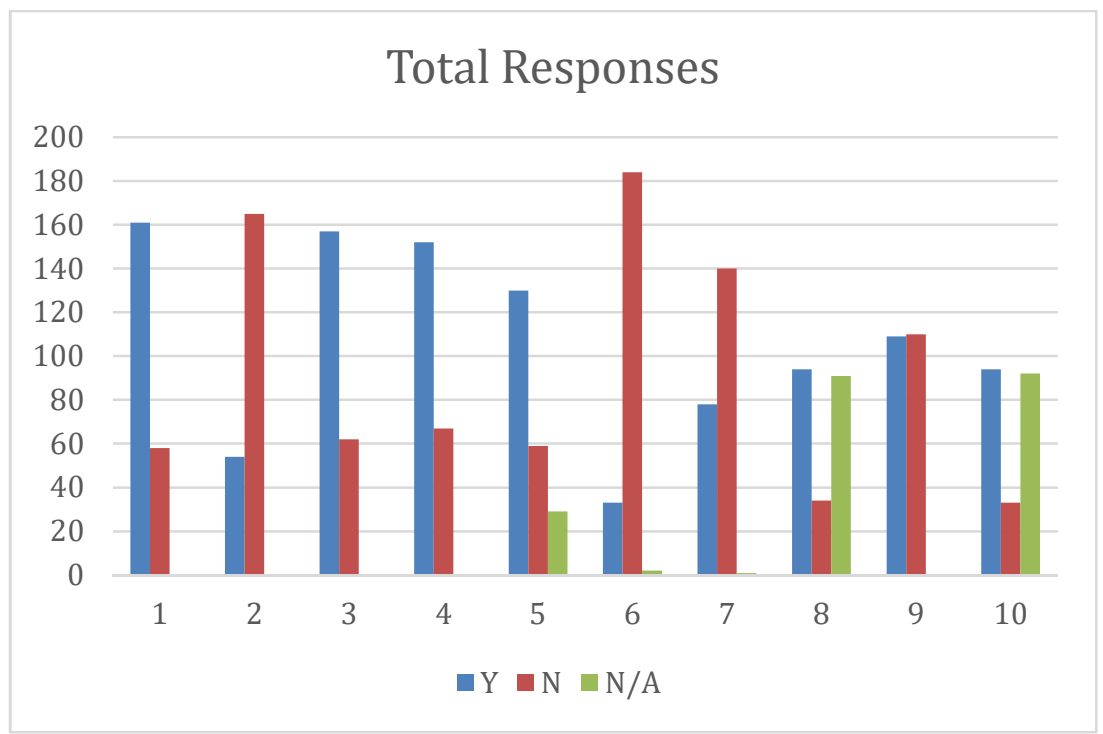

Figure 1.1

Of the 219 respondents, 157 have had major specific laboratory classes in other buildings, and 152 of them state that the major has its own space. It is not prudent to assume these are the same 152 students that have already taken a class with a lab, however it is highly likely this is the case. Furthermore, question 5 indicates that only 29 respondents selected N/A as a response, meaning their department does not have its own space. Comparing questions 4 and 5 in figures 1.2 and 1.3 shows that 130 students out of 152 with a departmental laboratory space feel included in the building. 


\section{Does your program/department have \\ its' own lab building?}

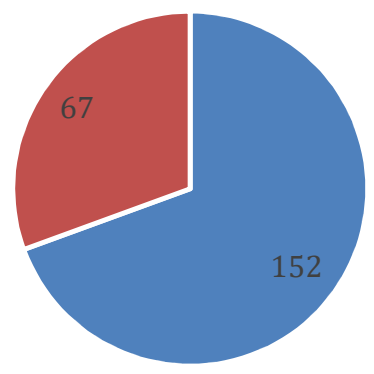

$$
\text { - Yes - No }
$$

Figure 1.2

\section{If yes, do you feel included in your program/department lab building?}

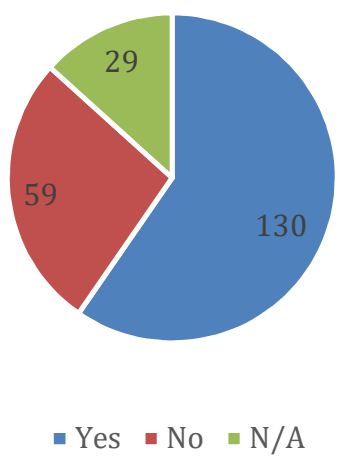

Figure 1.3

Questions 6 and 7 concentrated on the specific major of the student and the college overall. 84\% of the respondents indicated they do not feel isolated from other students in their major.

Similarly, 64\% stated they do not feel isolated from others in the college. The $20 \%$ drop is to be expected, as the classes surveyed were largely in a single division that do not take any classes with other divisions within the college. The most intriguing result is the response to question 8 . Figure 1.4 shows only a minority of the respondents feel that the new interdisciplinary building helps with inclusion. To the contrary, only $16 \%$ outright state that it does not. Many chose not to answer by selecting $\mathrm{n} / \mathrm{a}$, or have not had an opportunity to experience inclusion with others outside of their radius. Question 9 indicates that half of the students have not participated in interdisciplinary courses. Similar to question 8, question 10 is represented in figure 1.5 and is nearly identical, with only $15 \%$ stating that interdisciplinary courses do not increase learning. 


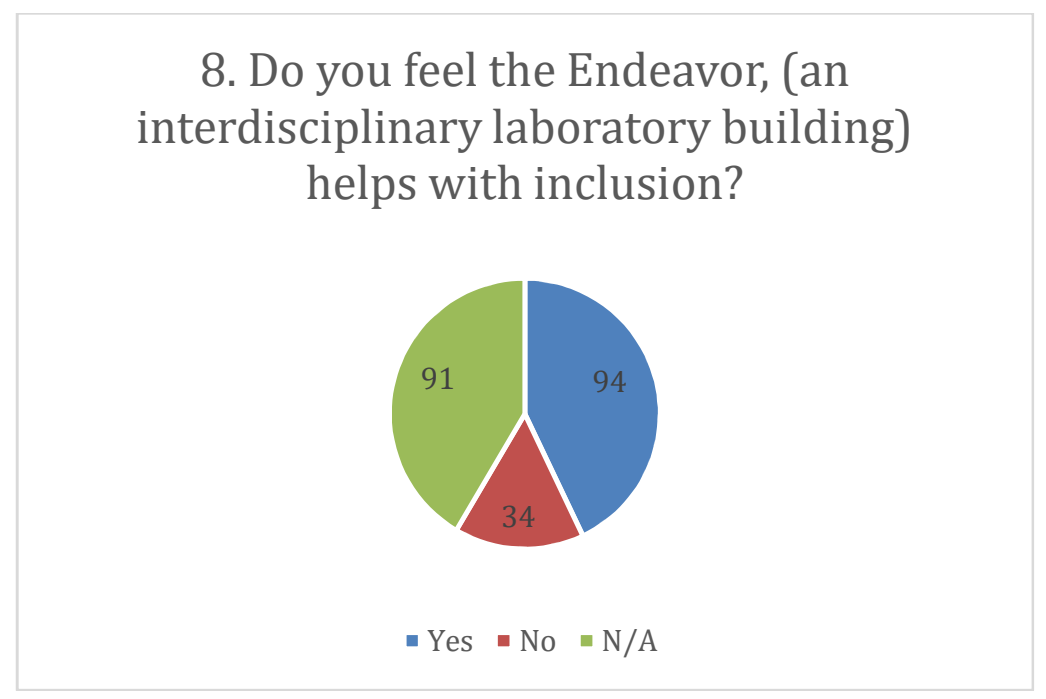

Figure 1.4

\section{Do you feel the interdisciplinary courses increase learning?}

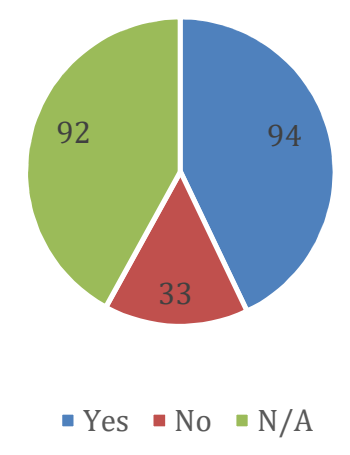

Figure 1.5

Discussion and Conclusion:

The new Endeavor laboratory building was designed and constructed with collegial interdisciplinary practices at the core of the programmatic focus. Faculty from across the college were involved in the initial design charrettes to determine how spaces would be used. When considering appropriate coursework for an interdisciplinary space, engineering and engineering technology programs investigated potential overlaps in curriculum. These courses have been taught with separate labs in the past as technology focuses more on application.

Further it was a requirement to think of the spaces as shared without traditional classroom space or time schedules. One classroom for pre-lab work has been provided per story in the three-story building. The different course focuses are evident in the lack of classroom or pre-lab space. While engineering courses rely on the labs solely for experiments, technology students may perform other functions in the during the lab period. Another difference is that technology 
faculty typically attend the labs, where engineering labs may be taught exclusively by graduate students.

The proposed non-traditional time scheduling is being utilized most effectively in a senior interdisciplinary design course which is offered as an elective across the college. This course is taught without a set schedule allowing the students to meet at the lab after traditional experimental lab courses are finished for the day. This senior design course was completed with students that did not participate in this survey, therefore further discussion regarding this utilization of the building is unnecessary at this moment.

Because there are three distinct divisions within the college, there are contrary views as to which division benefitted the most. This brief study gathered responses from 219 undergraduate students, 161 of which have at least visited the building. While largely speculation at this juncture after only a single semester, the data show that the majority of the undergraduate students do not feel isolation from other students in different majors as a hindrance to their education. The data indicates that separate buildings, classrooms or labs may help form cohorts which is indicated to help with college success through retention and grades (Spanierman et al. 2013). It is important to note that less than 1\% of respondents were not Engineering Technology majors. There were no respondents in Architecture or Engineering.

For future studies, the demographics will be used to cross-reference the major, gender and race with inclusion. Engineering and engineering technology are still lack minority role models (Chubin et al. 2005 and Foor et al. 2007). It is important to determine if cohorts or interdisciplinary learning affect minority students. Of the 219 students that responded, $75 \%$ selfidentify as Caucasian, and $93 \%$ are Male. While it is difficult to correlate student perceptions of inclusion from this limited study, there are several visual clues that were noticed by the authors that strongly suggests students do not consider cohorts, learning communities or so-called silos to be a negative impact on learning. In fact, most students form informal support groups using social media to increase success in courses. This could be another area of continued research.

In conclusion, there are several variables to include in order to properly address the terms inclusivity and isolation of learning. Race, gender, major, socio-economic status, and personality are all traits that contribute to self-identification of the student population. Generally the students will self-select their communities based on perceptions of success of their peers, not necessarily perceived success from academics. The results of this study indicate there is most definitely a gap in the literature concerning student perceptions of inclusion and diversity as it relates to learning. This study sets the table for continued work within the framework established.

References:

Chubin, D., May, G. and E. Babco. 2005. Diversifying the Engineering Workforce. Journal of Engineering Education. 94:1, 73-86. https://doi.org/10.1002/j.2168-9830.2005.tb00830.x

Felder, R. and Silverman, L. 1988. Learning and Teaching Styles in Engineering Education. Engineering Education, V. 78 (7), pp. 674-681. 
Foor, C., Walden, S., and D. Trytten. 2007. "I Wish that I Belonged More in this Whole Engineering Group:"Achieving Individual Diversity. Journal of Engineering Education. 96:2, 103-15. https://doi.org/10.1002/j.2168-9830.2007.tb00921.x

Goldman, C. 2012. A Cohort-based Learning Community Enhances Academic Success and Satisfaction with University Experience for First-Year Students. The Canadian Journal for the Scholarship of Teaching and Learning, 3:2. http://dx.doi.org/10.5206/cjsotl-rcacea.2012.2.3

Johnson, S. Luyben, W. and D. Talhelm. 1995. Undergraduate Interdisciplinary Controls Laboratory. Journal of Engineering Education. 84:2, 133-136. https://doi.org/10.1002/j.21689830.1995.tb00160.x

Klotz, L., Potvin, G., Godwin, A., Cribbs, J., Hazari, Z. and N. Barclay. 2014. Sustainability as a Route to Broadening Participation in Engineering. Journal of Engineering Education. 103:1, 137-153. DOI 10.1002/jee.20034

Mosier, R.D., Charter, V., Ramming, C.H., Reck, J. R., \& H.N. Yates. “Architecture, Architectural Engineering and Engineering Technology Student Learning Styles as Compared to Engineering Science Grades." Conference Proceedings, American Society for Engineering Education Midwest Section Conference, September 2017.

Nelson, J. and J. Lawson. 2013. Teaching Architecture, Engineering and Construction Disciplines: Using Various Pedagogical Styles to Unify the Learning Process. Conference Proceedings, American Society for Engineering Education Annual Conference \& Exposition, June 2013.

Schaub, D., Legg, S., Svoronos, S., Koopman, B., and S. Bai. 1999. Applying Total Quality Management in an Interdisciplinary Engineering Course. Journal of Engineering Education. 88:1, 107-112. https://doi.org/10.1002/j.2168-9830.1999.tb00419.x

Sharma, A. 2009. Interdisciplinary Industrial Ecology Education: Recommendations for an Inclusive Pedagogical Model. Asia Pacific Journal of Education. 29:1, 75-85, DOI: $10.1080 / 02188790802655056$

Spanierman, L. B., Soble, J. R., Mayfield, J. B., Neville, H. A., Aber, M., Khuri, L., and B. De La Rosa. 2013. Living learning communities and students' sense of community and belonging. Journal of Student Affairs Research and Practice, 50(3), 308-325. doi:10.1515/jsarp-2013-0022

Wawrzynski, M., and J. Jessup-Anger. 2010. From Expectations to Experiences: Using a Structural Typology to Understand First-Year Student Outcomes in Academically Based LivingLearning Communities. Journal of College Student Development. 51:2, 201-217. https://doi.org/10.1353/csd.0.0119 